\title{
Learning Through Play: An Educational Computer Game to Introduce Radar Fundamentals
}

\author{
Laurens Vercauteren ${ }^{1,2}$, Iñigo Cuiñas ${ }^{1}$, and Jo Verhaevert ${ }^{2}$ \\ ${ }^{1}$ Department of Signal Theory and Communications, Universidade de Vigo, 36310 Vigo, Spain \\ ${ }^{2}$ Department Industrial Technology and Construction, Faculty of Engineering Sciences and Architecture, \\ Ghent University, 9000 Gent, Belgium \\ E-mail: inhigo@uvigo.es
}

\begin{abstract}
The information exchange has evolved from traditional books to computers and Internet in a few years' time. Our current university students were born in this age: they learn and have fun with different methods as previous generations did. These digital natives enjoy computer games. Thus, designing games for learning some selected topics could be a good teaching strategy for such collective and also for undergraduate university students. This paper describes the development and test of an educational computer game revolving around radar. The objective of the game RADAR Technology is to teach students about the fundamentals of radar, while having fun during the learning experience. Based on the principle that you learn better what you practice, the authors want to induce students to discover a difficult to understand topic by proposing them a different experience, in a format better adapted to their generation skills. The computer game has been tested with actual students and the obtained results seem to be very promising.
\end{abstract}

Keywords: Computer applications; education; educational courses; radar theory

\section{Introduction}

$\mathbf{T}$ he history of higher education is directly related to information access and could be divided into four main ages dominated by key developments: the invention of writing, moveable type, mass printing, and Internet and computers [1]. The birth of writing allowed the transmission of large amounts of information from one generation to the following, and it relates to an education based on repetition and copying, only for selected people. The invention of moveable type could be related to the first universities born in Europe, in the Middle Age, focused on a few elite students. Then, two centuries ago, the mass printing development led to the expansion and extension of education all over the world. Most of our current universities are a result of such a push. However, we are now living in the Internet and computer age, and most of our teaching methods come from that previous era. Therefore, students,

Digital Object Identifier 10.1109/MAP.2015.2420492

Date of publication: 13 May 2015 and sometimes lecturers, are not specially attracted by some lessons or concepts that we are teaching year by year.

A clear example could be an introductory lesson to radar fundamentals: radar basics; signal routing and timing; ranging (maximum unambiguous range, radar waveform minimum range, slant range); direction determination (bearing, elevation angle); height of the target; accuracy; resolution (angular, range, resolution cell); theoretical maximum range equation (antenna gain and aperture, radar cross section, free-space path loss, external and internal losses); minimum discernible signal echo; noise; false alarm rate; or probability of detection. Those radar basis and concepts are observed to be difficult to understand for students. This fact has been detected more than two decades ago and its analysis allowed identifying a number of obstacles that explained such difficulty: the learning of any new subject, the organization of the provided material, the sometimes inadequate background of the students, the intrinsic complexity of the topic and the density of the concepts [2]. This early analysis indicates the interest and also the concern of many lecturers on how to improve the knowledge, skills, and understanding of 
radar students. When comparing proposals at the time of the analysis [3], and more than a decade later [4, 5], a short evolution could be observed: different authors published their ideas on teaching subjects related to radar and their methods are very similar. The three cited proposals are based on master classes on explaining the concepts and equations, helped by laboratory sessions complementing these classroom performances. The main differences are in the type of experimental sessions (i.e., software-based simulations or actual equipment).

Assuming the world around us is changing, teachers must look for new learning resources to make lessons more interesting, educational and fun. Learning through play is the pedagogical name of this trend and its academic results support the effort of adapting teaching techniques to its specifications.

Throughout this paper, the know-how of developing an educational game focused on learning the fundamentals of radar is presented and analyzed. The experience in teaching subjects on remote sensing fundamentals for a long time (more than 15 years) tells the authors that it is not easy to introduce the radar basis in one or two master-class sessions, while keeping the attention of the students: there are lots of concepts, equations, implications; and probably the session would be converted into a sequence of contents, too theoretical and boring! Thus, we explored a different strategy to provide the students with such radar contents, but allowing them to maintain the attention and also the interest in the subject.

Analyzing previous research on gamifying some parts of university subjects, there are several schemes, from adapting commercial games to supporting learning contents $[6,7]$, or solving problems based on simulation games [8] to more serious games designed to inspire concepts and values [9]. However, no deep experiences in gamifying radar basics have been found in previous literature. There are some experiences in development games for military applications, with the aim of training personnel to operate complex radar systems, in a cheaper way than using actual and very expensive equipment, but they are focused on a given device, and not reported in scientific literature. Nevertheless, there are lots of games, both professional and amateur, which take advantage of radar knowledge, to help the user detect elements around him or to virtually drive cars or other vehicles.

Section 2 analyzes the balance between educational games and traditional teaching, reinforcing the authors' belief that games can provide effective learning tools, as it has recently been stated $[10,11]$. These previous thoughts inspired the authors to design an ad hoc video game, which could provide players/learners with fun.

Section 3 contains the presentation of the game $R A D A R$ Technology. This game transports the students to around the mid-1900s to investigate the fundamentals of radar. This section relates the story, the learning experience and the gameplay. Different components of the game are highlighted and analyzed to get a better understanding of the game itself. The story of the game is also a big aspect for the students: if it is good enough, the player regards the learning experience as recreation, because he is having fun.

Section 4 is centered on an actual experience involving 34 students; some of them are volunteers from different university levels, and the rest are taking the course "Remote Sensing", for which the game has been designed. The results obtained by this test are analyzed and some conclusions about the use of such a strategy in actual circumstances are extracted.

Finally, Section 5 provides the conclusions of this paper, related to game development, its usability for teaching radar fundamentals and the results of the trials.

\section{Educational Games and Traditional Teaching}

For various generations, sons and daughters had similar jobs as their parents or grandparents did, but they also lived and recreated in similar ways. Nowadays, our children live, play, and relax completely differently than their grandparents. Therefore, current university staff has attended major changes in our societies throughout the last few decades. Many of these changes came with computers and the progressive digitalization of our lives. This breathing evolution has infiltrated also in education, as teachers are trying to lecture students that have very different skills than themselves. Lecturers have classrooms full of digital natives and this situation is probably the largest change in centuries of university history: higher education expanded with the impulse of mass printing, which allows people to access knowledge through books, but nowadays, Internet and computers are a must-have for getting access to information. Those new students, with new abilities, demand also new learning tools and strategies: the new society has changed the way we think and learn [12].

Among these social changes, the scope of education cannot be static in its habits: traditional tutoring is a result of decades of experience. In fact, traditional education uses exactly the same methods that were applied to our grandparents. As living modes changed a lot during the last decade, traditional education methods could be boring for a new generation of students.

A paper just written at the beginning of the Internet age tried to investigate the ability of computers to help students to understand Electromagnetism [13]. It was too early to talk about educational games, but not to consider the use of educational software as a compelling idea. Among the lessons learned by the author, the active involvement of the student in the education process seems to be essential. Our current students belong to a generation that loves to play computer games; so, the active implication in playing a game could be assumed. The challenge is to get advantage of our students' abilities in playing video games to provide them with an educational experience: if educational games gave fun to the players, they would play a lot and learn the underlying subjects at the same time. 
The use of video games to involve students into interactive environments, where they can play and learn, explore possibilities never thought of one decade ago. When we incorporate computers with educational games to the learning experience, the traditional learning session moves to a student-driven situation, where he has to be an actor in order to progress. Thus, learning becomes more effective when the learners are not passive subjects; as the process takes advantage of students' abilities.

The motion from master classes to gamed classes is psychologically interesting: playing a game is a voluntary and enjoyable activity [14], which motivates the players (i.e., students) to be connected to the mission [15-17]. Thus, a well-designed educational game can attract the attention better than a qualified lecturer. However, games are not commonly played in classrooms due to several reasons. Some of these reasons are related to the fun the game provides: many educational games are not really games, but only give the same class contents with colors and some technological advances; hence, the students are not playing a game, they only make another task [11]. In addition, many people have a bad connotation of games as they think the games promote violent behavior [18-21]. Finally, there are educators who want to preserve the link between the learning experience and the traditional learning places, which would be cut by the education gamifying [22].

Nevertheless, educational computer games can provide more interesting environments for knowledge than traditional methods [23-33], speaking to our students in a language they are used to. However, the objective must not be limited to the packaging, as the value of well-designed and well-implemented tools depends on how they are integrated into the course [13]. The design of such an educational game must preserve the aim of education: help students to get skills to develop professional careers in a natural way. Having fun is an added value, but it is not the objective: it is just the path.

\section{Components of the Game}

Along this work, a personalized platform adventure game has been developed using the engine GameMaker 8.1 by YoYo Games Ltd [34]. The goal was to teach students the fundamentals of radar and the designed game has been called RADAR Technology. The game is freely available at http://www. sistemasradio.com and can be found in the "downloads" section.

\subsection{Story and Learning Experience}

In the game RADAR Technology, the students learn about the fundamentals of radar by reading a text on an ingame computer and by interacting with nonplayer characters (NPCs): the robots. The game situates its action in the mid1900 s, when radar is under development. The player gets the role of a secret agent at the agency Super-Secret Agency (SSA), which calls him to complete a mission (Figure 1 shows the agent, i.e., a worm, going toward the agency).

The target of the agency is RADAR Inc., a company that is researching in radar technology and has valuable information not yet publishable to the world. Security at RADAR Inc. detected another SSA-spy during his mission, and they kidnapped him. Now, the mission of the player is to get his colleague out of there. The agency found out that a scientist fell ill; thus, the player has to dress up as that scientist (Dr. Doppler) and infiltrate the enemy headquarters, as the boss explains him in Figure 2.

Before he was captured, the other spy told that the company had security robots anywhere in the building, asking questions on radar fundamentals to every person (scientist or not) who comes across. Then, the robots use the responses to detect intruders, as all scientists at the place are experts in radar fundamentals. Thus, the player must learn the fundamentals of radar, and he does it using the documentation prepared by a group of top scientists, based on the contents of [35, 36], and presented in web-page format documents. Thus, the student learns about signal routing, signal timing, ranging, direction determination, height, accuracy, resolution, the theoretical maximum range equation, false alarm rate, and the probability of detection. This takes around 15 to $30 \mathrm{~min}$.

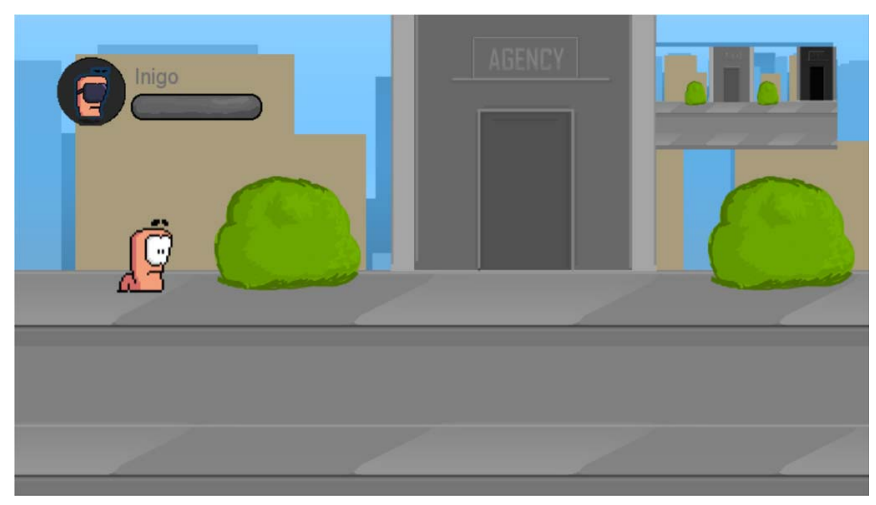

Figure 1. The agent going to the Agency to receive his mission.

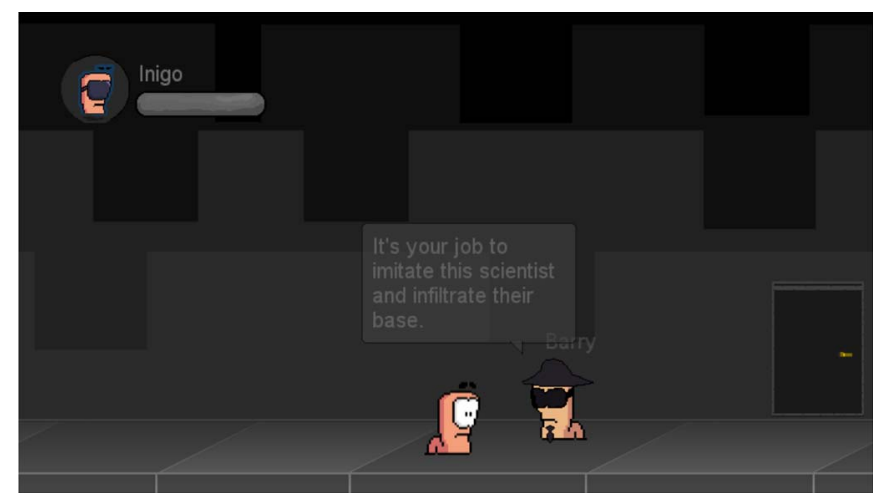

Figure 2. Agent Barry explaining to the player the mission he has to complete. 


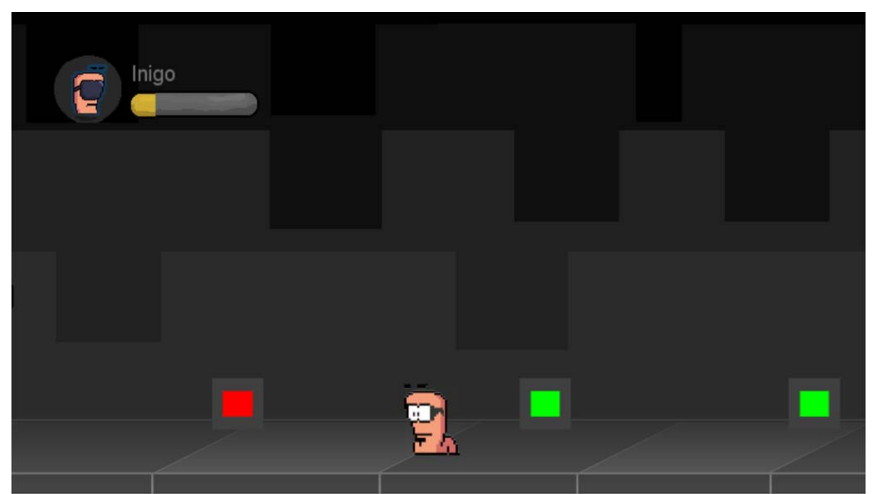

Figure 3. The player passed two robots (in green), and another is waiting for him (in red).

When the player thinks his radar knowledge is good enough, he walks to the company RADAR Inc. and must try to answer the questions of the security robots, represented by colored boxes. They are in green when the player has completed the questions, and in red when the player has to stop and answer, as depicted in Figure 3. The questions are extracted from various sources $[35,36]$.

The player has to pass about seven rooms, with two to three robots in each room, in order to reach the spy's prison cell. When he meets the spy, the player just has to give him some lock picks, thus he can escape. At the end, the player gets his final report containing his score.

\subsection{Questions}

There are four kinds of questions that the player must answer correctly throughout the game: multiple choices, true or

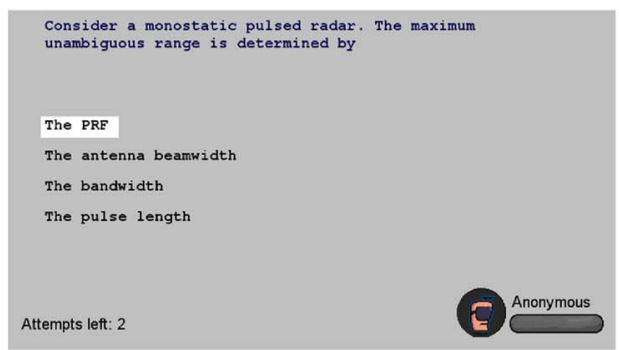

(a)

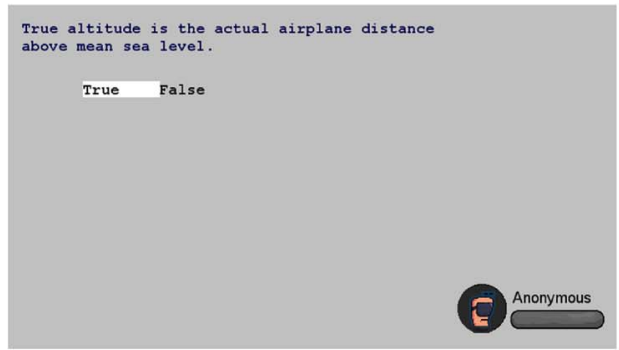

(c) false, gap fills and matching. There are roughly 60 questions in the game of which 20 questions will be asked each time the players plays the game, evenly distributed among the four types. Each robot selects a random question. However, if the selected question has already been asked, the robot will try to ask a new one, not asked before to that player. This design is to prevent the students from solving the questions together when they are in the same classroom. It also assures some kind of replayability to the game, as you do not get the same questions all the time. Next paragraphs describe the different types of questions. Figure 4 shows examples.

- Multiple choice: the robot asks a question and the player can choose one answer among four different options.

- Gap fill: the robot says an incomplete sentence and the player has to fill in the correct word, to complete the assertion.

- True or false: in this case the player gets three successive questions and has to say whether each of the statements the robot says, is true or false.

- Matching: the robot shows four concepts and four related ideas and the objective is to order the related choices, linking them to those provided by the robot.

\subsection{Gameplay}

RADAR Technology is a 2-D platform game. The student has control over the player character by pressing the arrow keys. He can interact with objects and NPCs by pressing the space bar.

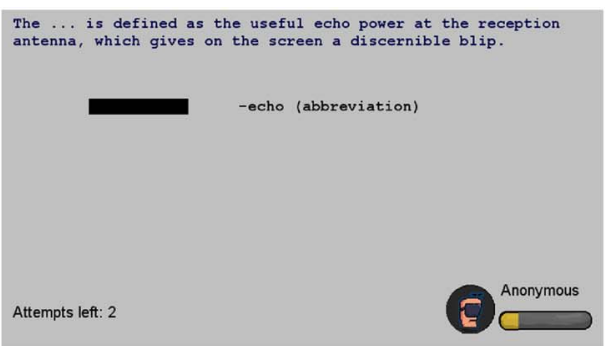

(b)

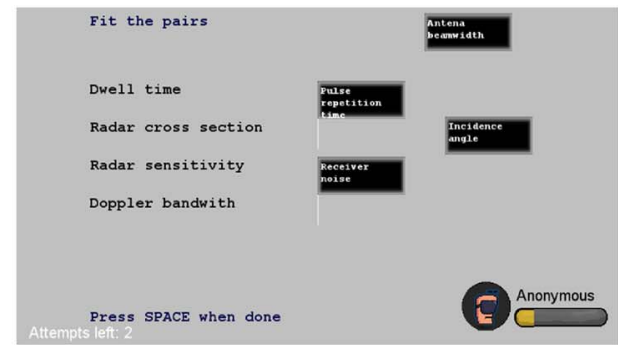

(d)

Figure 4. Questions from the robots. (a) Multiple choice. (b) Gap fill. (c) True or false. (d) Matching. 
The player starts with ten lives and every failed answer subtracts one life. If the player runs out of lives, the security bots, as indicated in Figure 5, detect him. This means that the game is over.

However, a player must develop the capacity to learn from mistakes to be successful at video gaming. Thus, the game allows the player to begin again, but with some penalty due to the previous detection. When accomplishing the mission, the final score (see Figure 6) is composed of four elements: the time for completing the game, the amount of game overs, the number of kept lives and the number of questions answered correctly. Such score system encourages the student to execute the required task in a good way. He can even compete with his mates.

\section{Actual Tests of the Radar Game}

Two sets of students responded to validate the game. Both sets of testers were asked to play the game and to pass a test on radar concepts, one before playing the game and one afterward.

A group of 20 students at various educational levels voluntarily joined set A. Most of them are current undergraduate students $(50 \%)$, some are working toward their Master degrees $(30 \%)$ and the others finished that degree in the last three years and are working on their Ph.D. thesis research (20\%).

Fourteen students enrolled in a subject called "Remote Sensing" (taught in the last year of the Bachelor on Telecommunication Technologies Engineering, a four-year course) joined set B. They played the game to obtain an assessment on their individual knowledge about radar concepts, which represents $10 \%$ of the topic's final grade.

\subsection{Design}

The students were seated in a laboratory for an individual experience, defined in three steps.

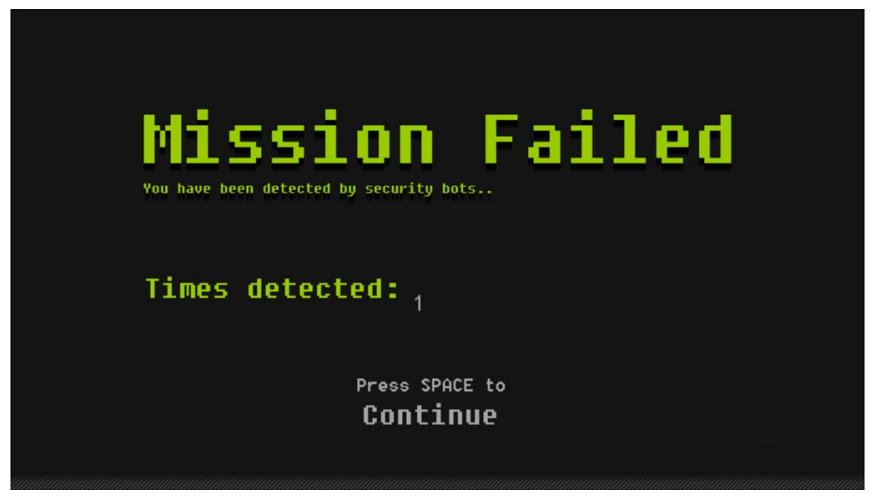

Figure 5. The game is over when the security robots subtract all your lives.

\section{Hission Accomplished}

you have rescued our agent.

Hission time $=20000$

Times detected: 0

Lives left: 10000

Borrect questions: 20000

Credits

Figure 6. When the player accomplishes the mission, the final score provides detailed information.

- First, a test on radar fundamentals was individually accomplished. The test consisted of ten questions, following a multiple-choice scheme, as indicated in the appendix. The use of multiple-choice examinations has been previously analyzed, demonstrating that it represents a fair and realistic way to assess the students' learning that additionally afforded saving in staff labor [37].

The Professor in charge of the subject "Remote Sensing" selected the questions among a collection from exams of previous years, quizzes and questions at radar texts, and the contribution of several lecturers and researchers. We aimed at covering most of the knowledge incorporated in the game, being exhaustive to be sure the students would not guess the answers correctly, but they have understood the concepts.

Once finished, the tests were corrected by a Professor, with similar rubrics as a regular exam on the topic, and the qualifications are identified by

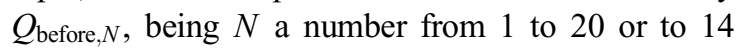
(set A or B, respectively) that univocally identifies each student. Thus, the tests were identified by a code and then the Professor could not relate the author of the test to the persons participating in the experience: the correction followed a blind procedure. The qualifications range from 0 to 10 .

- Then, each student played the game. The students were allowed to play again when game over and some of them played for almost 2 hours to win the game. They were free to leave the lab when they wanted, but they were pleased to conclude the third stage of the experience. The person who left the room first, stayed around $30 \mathrm{~min}$ in the experience and he won the game! Only two were not able to finish the game, due to PC failures.

- $\quad$ Finally, the same test was passed again, with exactly the same questions as the previous one (although students did not know this fact in advance). Then, the exam qualifications are identified by $Q_{\text {after }, N}$, being $N$ the same identifier than previously used for each student. Again, blind correction was guaranteed. 


\subsection{Results}

Some statistics were extracted from the qualifications of the tests, as the mean values of $Q_{\text {before }}$ and $Q_{\text {after }}$. Before playing, students got mean qualifications as 5 and 4.7 for sets $\mathrm{A}$ and B, respectively; whereas after playing they increased to 6.9 and 7.0. The results have been also analyzed in terms of qualification bands, grouping the grades as commonly done in regular exams: those under 5 , where examinees failed; between 5 and 7 , where they passed; from 7 to 9 , which grade is distinction; and over 9, which is high distinction. The distribution of such results is summarized in Table 1.

Figures 7 and 8 graphically depict the evolution of the scores before and after playing the game, for set $\mathrm{A}$ and $\mathrm{B}$, respectively. A remarkable observation is that the peak on the diamond curves has rotated from just passed to better qualifications (distinction and high distinction), regardless the set of students. This is observed in the rotation of the diamond graph. The number of outstanding students (high distinction) was 0 before playing and 4 or 2 , depending on the set (A or B) after doing it, and the number of distinguished students changed from 3 to 9 , or from 1 to 8 . In addition, the number of students who failed the exam, has dramatically been reduced (from 7 or 6 to only 1 in both cases), which is very significant. These appreciations indicate that the academic results of the game seem to be very promising.

Tables 2 and 3 summarize mean, median and standard deviation of individual grades, disaggregated by sets of students, A and B, respectively. A first observation of such values indicates that the difference between results before and after trying the game appear to be well within the limits of the standard deviation. Therefore, it appears that there are no differences between groups. However, both series are not strictly independent, as data in each series is closely related by pairs. The gap between pairs of grades obtained by each student is what defines the validity of the proposal. Thus, the first-order statistics of $\Delta Q$ (the degree of individual improvement for each of the students: $\left.\Delta Q_{N}=Q_{\text {after } N}-Q_{\text {before }, N}\right)$ are then extracted: mean, median, and standard deviation. This is shown in Table 2 for set A and Table 3 for set B. The mean of $\Delta Q$ is positive in both collections of data, which indicates that the game has also positive effects on the students' performance. In addition, the difference between mean and standard deviation is always larger than or equal to zero, corroborating the previous assertion: playing the game brings positive academic results for most of the testers.

Table 1. Number of students obtaining different qualification bands.

\begin{tabular}{ccccc}
\hline \hline \multirow{2}{*}{ Qualifications } & \multicolumn{2}{c}{ Set A } & \multicolumn{2}{c}{ Set B } \\
\cline { 2 - 5 } & before & after & before & after \\
\hline $\mathrm{Q}<5$ & 7 & 1 & 6 & 1 \\
$5<=\mathrm{Q}<7$ & 10 & 6 & 7 & 3 \\
$7<=\mathrm{Q}<9$ & 3 & 9 & 1 & 8 \\
$\mathrm{Q}>=9$ & 0 & 4 & 0 & 2 \\
\hline \hline
\end{tabular}

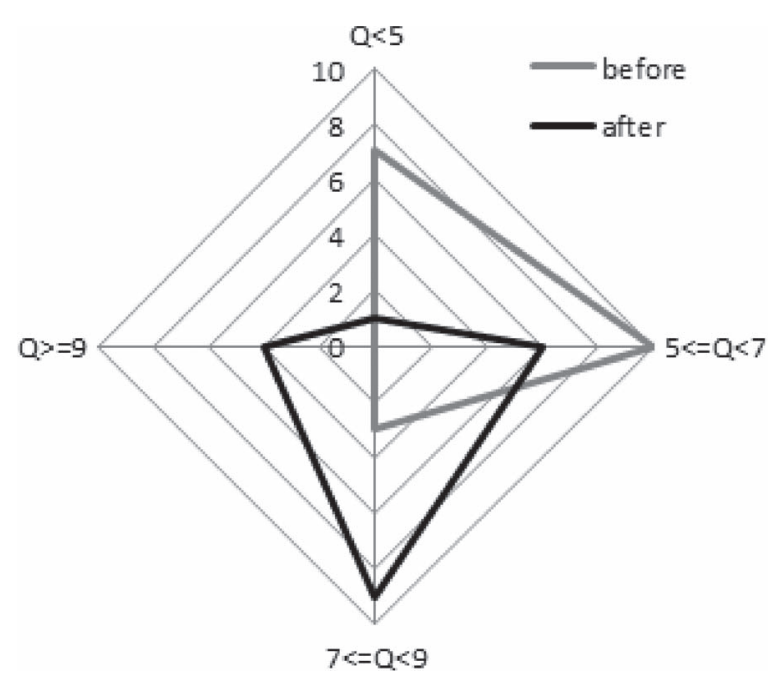

Figure 7. Evolution of scores before and after playing the game, set $\mathbf{A}$.

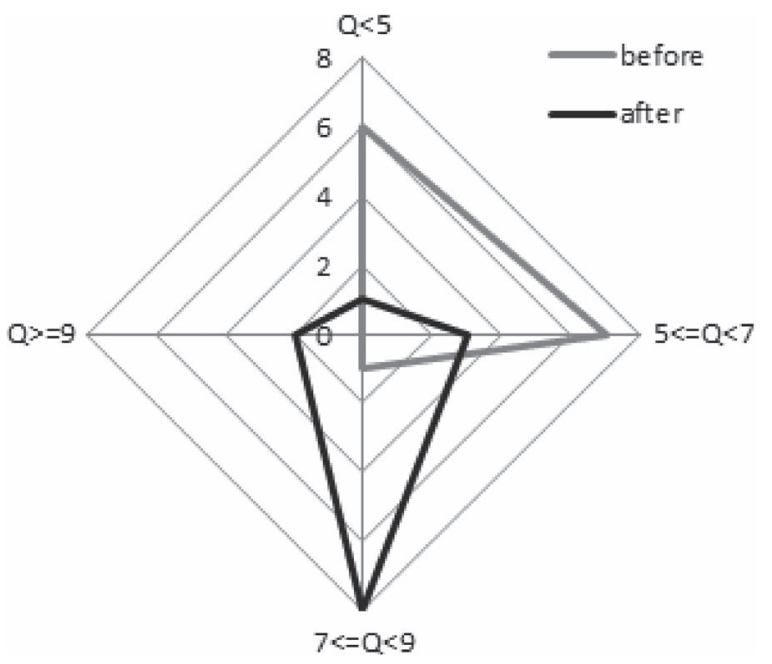

Figure 8. Evolution of scores before and after playing the game, set $B$.

Table 2. Evolution of scores before and after playing, set A.

\begin{tabular}{lllcl}
\hline \hline & \multicolumn{2}{l}{ Qualifications } & \multicolumn{2}{l}{$\Delta \mathrm{Q}$} \\
\cline { 2 - 5 } & before & after & absolute & $\%$ \\
\hline Mean & 5.0 & 6.9 & 1.9 & $38 \%$ \\
Median & 5.0 & 7.0 & 2.0 & $40 \%$ \\
Std. Dev. & 1.5 & 1.9 & 1.9 & \\
\hline \hline
\end{tabular}

Table 3. Evolution of scores before and after playing, set $\mathbf{B}$.

\begin{tabular}{lllcl}
\hline \hline & \multicolumn{3}{l}{ Qualifications } & \multicolumn{2}{l}{$\Delta \mathrm{Q}$} \\
\cline { 2 - 5 } & before & after & absolute & $\%$ \\
\hline Mean & 4.7 & 7.0 & 2.3 & $63 \%$ \\
Median & 5.0 & 7.5 & 2.0 & $40 \%$ \\
Std. Dev. & 1.3 & 1.7 & 1.8 & \\
\hline \hline
\end{tabular}


Table 4. Improvement in the scores before and after playing.

\begin{tabular}{lcc}
\hline \hline \multirow{2}{*}{$\Delta$} & \multicolumn{2}{c}{ students whose grade is improved } \\
\cline { 2 - 3 } & Set A & Set B \\
\hline$<0 \%$ & 2 & 1 \\
$0-25 \%$ & 6 & 1 \\
$25-50 \%$ & 4 & 6 \\
$50-75 \%$ & 5 & 3 \\
$>75 \%$ & 3 & 3 \\
\hline \hline
\end{tabular}

Table 4 shows the number of students who improve their grades by different percentages (i.e., the distribution of $\Delta Q$ ). It is remarkable that only 2 of 20 and 1 of 14 (sets A and $\mathrm{B}$, respectively) obtained worse results in the exam answered after playing than in that made before; and besides, improvements of more than $50 \%$ of the original grade are reached by $40 \%$ (set A) and $42 \%$ (set B) of the testers.

Figures 9 and 10 both show pie charts summarizing the previously commented result.

\subsection{Analysis}

Analyzing the results, some conclusions could be extracted. As more than $90 \%$ of $\Delta Q_{N}$ are positive, the game seems to reach its objective: the results indicate it is a useful tool for learning radar fundamentals. Aggregating both tests, only three students out of 34 scored lower on the final test than on the first test and only one among those fighting for an actual grade, as it was the case in set B. Thus, the objective evaluation is positive: the video game was designed to learn about radar technologies and testers of the game have learned, independent of their previous knowledge.

However, a subjective evaluation must be also made. This evaluation comes from the observation of the lecturers, but also from the comments provided by the students acting as game testers. There were some interesting annotations made during both experiments. Whenever a student found a question that he could not solve or he considered too difficult, he would look at

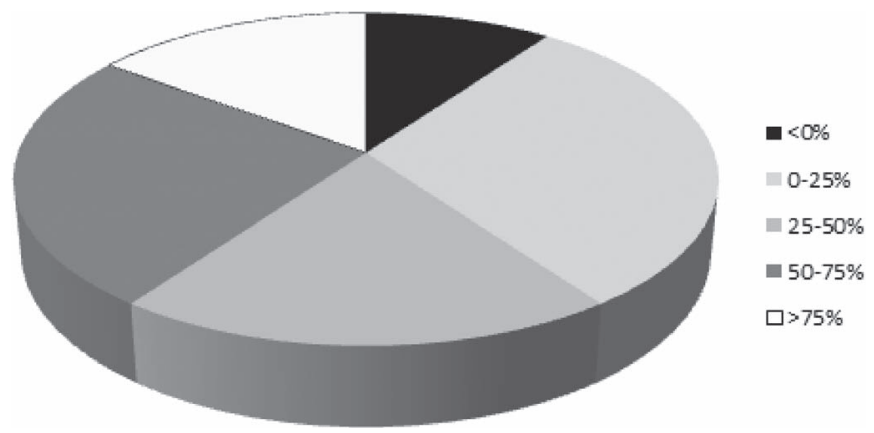

Figure 9. Improvement in scores before and after playing, set $\mathbf{A}$.

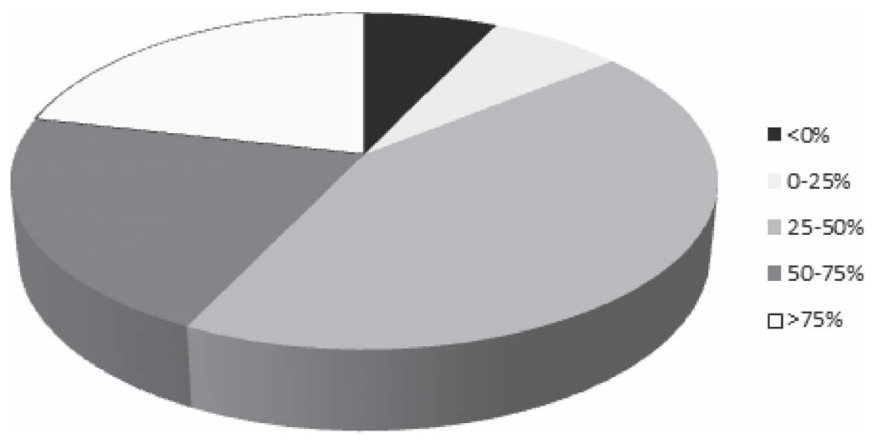

Figure 10. Improvement in scores before and after playing, set $B$.

the screen of the student next to him, looking for some collaboration. However, because the questions were generated randomly, they were not able to cheat. The student always had the opportunity to restart, whenever he failed the mission. A common trend was that most of the students restarted if they failed at the game: the testers were involved enough in the game to be forced to win it. This is very interesting, as it denotes the game caught the attention of all participants. Some students became more frustrated at the end when they got a game over, but most of them tried again. When they finished the game, they were quite happy.

The feedback of the students was very positive. Most of the opinions were focused on the usefulness of the game: the efficiency of the learning by trial and error technique, the clarity of the questions and the easy playing.

\section{Conclusion}

This paper has presented the design and test of a computer game to teach radar fundamentals at university. The result is a game called RADAR Technology, and it applies the principles of learning through play. The game is freely available at http://www.sistemasradio.com and can be found in the "downloads" section.

A complete game has been developed, researching the fundamentals of radar, analyzing the different game structures and models, preparing a story that induces the students to play, introducing characters that add a humoristic touch, and also testing the game with two sets of volunteers and actual students at the School of Telecommunication Engineering of the University of Vigo.

The test of the game provided us with promising results, as the participating students objectively improved their knowledge on radar, which was the aim. In fact, $38 \%$ of the students failed the exam before playing the game, and only $6 \%$ failed after playing. In addition, the grades of the exams moved from passed to distinction ones.

The testers' comments and suggestions provide some improvements to the final version of the game. Anyway, the 
conclusion is that the game accomplished its objective: the students learn more.

\section{Acknowledgement}

The authors would like to thank Mr. A. Elyamani for his assistance in developing the educational computer game. The authors also thank Mr. S. Van Lent for the implementation of music for the game. In addition, the authors would like to express their gratitude to the students that participated in testing our game and took two exams.

\section{Appendix: Test to Assess the Students}

This test was designed to assess the students' knowledge. It consisted of ten questions. Each question has only one correct answer. The selected questions were those listed as follows:

1. What does "D" mean in the acronym radar?
a. Direction
b. Duration
c. Detection
d. Design

2. Consider a monostatic pulsed radar. The maximum unambiguous range is determined by
a. The PRF
b. The antenna beamwidth
c. The bandwidth
d. The pulse length

3. Consider a monostatic pulsed radar. The minimum range an object can be detected is determined by
a. The pulse length
b. The PRT
c. The antenna beamwidth
d. The pulse bandwidth

4. The radar cross section of a target depends on
a. The radar pulse length
b. The pulse repetition frequency
c. The transmitted power
d. The operating radar wavelength

5. Which kind of antenna would you use in a radar system?
a. Isotropic
b. Omnidirectional
c. Directional
d. Hemispheric

6. What is the meaning of the second " $\mathrm{R}$ " in radar?
a. Radio
b. Ranging
c. Reverberation
d. Return

7. The time that a target is illuminated by the antenna beam during one scan, is called:
a. Day time
b. Dwell time
c. Illumination time
d. Duration time

8. What parameter is related to Doppler bandwidth?
a. Antenna bandwidth
b. Incidence angle
c. Receiver noise
d. Pulse repetition time

9. What parameter is improved by the synthetic aperture technique?
a. Range resolution
b. Azimuth resolution
c. SNR
d. Target interference reduction

10. What parameter is improved when the transmitted pulse bandwidth increases?
a. Range resolution
b. SNR
c. Azimuth resolution
d. Antenna length

\section{References}

[1] R. Darnton, "The research library in the digital age" Harvard Univ. Library, Cambridge, MA, USA, 2008.

[2] S. Quegan and S. Kingsley, "What do Young Radar Engineers Find Difficult?" in Proc. Inst. Elect. Eng.-Colloq. Educ. Radar Sonar, 1992, pp. $3 / 1-3 / 4$.

[3] H. D. Griffiths, "A Multidisciplinary Approach to Education in Radar," in Proc. Inst. Elect. Eng. - Colloq. Educ. Radar Sonar, 1992, pp. 4/1-4/4.

[4] A. J. Camps, "A Radar Course to Undergraduate level: An Approach to Systems Engineering," IEEE Trans. Educ., vol. 46, no. 4, pp. 497-501, Nov. 2003.

[5] M. A. Solano, J. S. Ipina, J. M. Zamanillo, and C. Perez-Vega, "X-Band Gunn Diode Oscillator for a Multiple-Frequency ContinuousWave Radar for Educational Purposes," IEEE Trans. Educ., vol. 45, no. 4, pp. 316-322, Nov. 2002.

[6] F. Ke, "Computer-Game-Based Tutoring of Mathematics," Comput. \& Educ., vol. 60, no. 1, pp. 448-457, Jan. 2012. 
[7] K. Squire, "Replaying history: Learning world history through playing civilization III," Ph.D. dissertation, Indiana Univ., Indianapolis, IN, USA, 2004.

[8] K. Kiili, "Foundation for Problem-Based Gaming," Brit. J. Educ. Technol., vol. 38, no. 3, pp. 394-404, May 2007.

[9] D. W. Shaffer, "Studio mathematics: The epistemology and practice of design pedagogy as a model for mathematics learning," Wisconsin Center Educ. Res., Madison, WI, USA, Working paper, No. 2005-3, 2005.

[10] J. Gee, What Video Games Have to Teach Us About Learning and Literacy. New York, NY, USA: Palgrave, 2007.

[11] K. Squire, "Video Games in Education," Int. J. Intell. Games Simul., vol. 2, no. 1, pp. 49-62, 2003.

[12] D. W. Shaffer, R. Halverson, K. R. Squire, and J. P. Gee, "Video games and the future of learning," Wisconsin Center Educ. Res., Madison, WI, USA, Working paper, no. 2005-4, 2005.

[13] J. F. Hoburg, "Can Computers Really Help Students Understand Electromagnetics?" IEEE Trans. Educ., vol. 36, no. 1, pp. 119-122, Feb. 1993

[14] M. B. Kinzie and D. R. D. Joseph, "Gender Differences in Game Activity Preferences of Middle School Children: Implications for Educational Game Design," Educ. Technol. Res. Develop., vol. 56, no. 5/6, pp. 643-663, Dec. 2008.

[15] B. Hoffman and L. Nadelson, "Motivational Engagement and Video Gaming: A Mixed Methods Study," Educ. Technol. Res. Develop., vol. 58, no. 3, pp. 245-270, Jun. 2010.

[16] W. H. Huang, W. Y. Huang, and J. Tschopp, "Sustaining Iterative Game Playing Processes in DGBL: The Relationship Between Motivational Processing and Outcome Processing," Comput. \& Educ., vol. 55, no. 2, pp. 789-797, Sep. 2010.

[17] S. J. Warren, M. J. Dondlinger, and S. A. Barab, "A MUVE Toward PBL Writing: Effects of a Digital Learning Environment Designed to Improve Elementary Student Writing," J. Res. Technol. Educ., vol. 41, no. 1, pp. 113-140, 2008.

[18] B. Bartholow and C. Anderson, "Effects of Violent Video Games on Aggressive Behavior: Potential Sex Differences," J. Exp. Soc. Psychol., vol. 38, no. 3, pp. 283-290, May 2002.

[19] C. Anderson, "An Update on the Effects of Playing Violent Video Games," J. Adolescence, vol. 27, no. 1, pp. 113-122, Feb. 2004

[20] D. Gentile, P. Lynch, J. Linder, and D. Walsh, "The Effects of Violent Video Game Habits on Adolescent Hostility, Aggressive Behaviors, and School Performance," J. Adolescence, vol. 27, no. 1, pp. 5-22, Feb. 2004.

[21] W. Bosche, "Violent Video Games Prime Both Aggressive and Positive Cognitions," J. Media Psychol. Theories, Methods Appl., vol. 22, no. 4, pp. 145-150, 2010.

[22] T. Barko and T. Sadler, "Practicality in Virtuality: Finding Student Meaning in Video Game Education," J. Sci. Educ. Technol., vol. 22, no. 2, pp. 124-132, Apr. 2013.

[23] N. E. Cagiltay, "Teaching Software Engineering by Means of Computer-Game Development: Challenges and Opportunities," Brit. J. Educ. Technol., vol. 38, no. 3, pp. 405-415, May 2007.

[24] F. Ke, "A qualitative meta-analysis of computer games as learning tools," in Handbook of Research on Effective Electronic Gaming in Education, R. E. Ferdig. New York, NY, USA: IGI Global, 2008, pp. 1-32.

[25] A. Armory, K. Naicker, J. Vincent, and C. Adams, "The use of Computer Games as an Educational Tool: Identification of Appropriate Game Types and Game Elements," Brit. J. Educ. Technol., vol. 30, no. 4, pp. 311-321, Oct. 1999.

[26] A. Hanning, N. Kuth, M. Ozman, S. Jonas, and C. Spreckelsen, "eMedOffice: A Web-Based Collaborative Serious Game for Teaching Optimal Design of a Medical Practice," BMC Med. Educ., vol. 12, p. 104, 2012.

[27] S. Rondon, F. Sassi, and C. Andrade, "Computer Game-Based and Traditional Learning Method: A Comparison Regarding Students' Knowledge Retention," BMC Med. Educ., vol. 13:30, no. 56, pp. 643-663, 2013.

[28] H. Sung and G. Hwang, "A Collaborative Game-Based Learning Approach to Improving Students' Learning Performance in Science Courses," Comput. \& Educ., vol. 63, pp. 43-51, Apr. 2013.

[29] C. G. Von Wangenheim, R. Savi, and A. Borgatto, "DELIVER!-An Educational Game for Teaching Earned Value Management in Computing Courses," Inf. Softw. Technol., vol. 54, no. 3, pp. 286-298, Mar. 2012

[30] M. Fisch, "Making Educational Computer Games' Educational," in Proc. Conf. Interact. Des. Children, 2005, pp. 56-61.

[31] K. Sung et al., "Game-Themed Programming Assignment Modules: A Pathway for Gradual Integration of Gaming Context Into Existing Introductory Programming Courses," IEEE Trans. Educ., vol. 54, no. 3, pp. 416-427, Aug. 2011.
[32] J. Gonzalez et al., "The use of Video-Gaming Devices as a Motivation for Learning Embedded Systems Programming," IEEE Trans. Educ., vol. 56, no. 2, pp. 199-207, May 2013.

[33] B.-S. Jong, C.-H. Lai, Y.-T. Hsia, T.-W. Lin, and C.-Y. Lu, "Using Game-Based Cooperative Learning to Improve Learning Motivation: A Study of Online Game use in an Operating Systems Course," IEEE Trans. Educ., vol. 56, no. 2, pp. 183-190, May 2013.

[34] YoYo Games GameMaker Studio, Jun. 2013, http://www.yoyogames. com/gamemaker/studio

[35] C. Wolff, http://www.radartutorial.eu, Jun. 2013

[36] B. R. Mahafza and A. Z. Elsherbeni, "Simulations for Radar Systems Design," Boca Raton, FL, USA: Chapman \& Hall/CRC Press, 2000.

[37] P. S. Excell, "Experiments in the use of Multiple-Choice Examinations For Electromagnetic-Related Topics," IEEE Trans. Educ., vol. 43, no. 3, pp. 250-256, Aug. 2000.

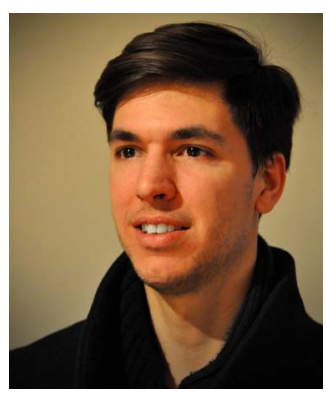

Laurens Vercauteren was born on May 16 , 1991 and received the Master of Science in industrial engineering: electronics-ICT from the Ghent University, Gent, Belgium.

He has an interest in developing computer games. In 2013, he was an Erasmus student with the Master in Signal Theory and Communications, University of Vigo, Vigo, Spain, where he performed his Master Thesis. He is currently studying Master of Science in business economics.

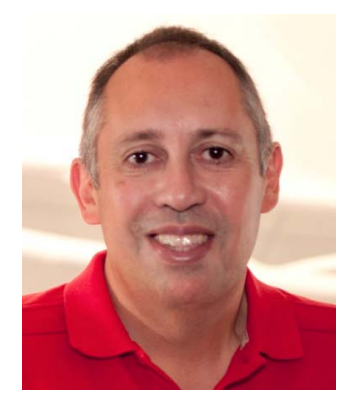

Iñigo Cuiñas (M'08-SM'14) was born in Vigo, Spain, in 1971. He received the degree in telecommunication engineering in 1996 and the Ph.D. degree in 2000, both from the University of Vigo, Vigo, Spain.

His research interests are the propagation of radio waves in complex environments; the environmental implications of radio systems, as the development of techniques to reduce the electromagnetic pollution; the extension of the use of radio technologies in rural environments; and remote sensing.

$\mathrm{He}$ is currently a Professor with the Department of Signal Theory and Communications, University of Vigo. He is also a Dean with the School of Telecommunication Engineering, where he teaches courses on remote sensing and electromagnetic field measurements.

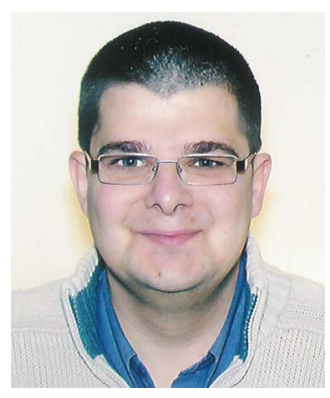

Jo Verhaevert received the engineering and Ph.D. degrees in electronic engineering from the Katholieke Universiteit Leuven, Leuven, Belgium, in 1999 and 2005, respectively.

$\mathrm{He}$ is currently a Professor and teaches courses on telecommunication with the Department of Industrial Technology and Construction, Faculty of Engineering Sciences and Architecture, Ghent University, Belgium, where he also performs research. His research interests include indoor wireless applications (such as Wireless Sensor Networks), indoor propagation mechanisms and smart antenna systems for wireless systems. ${ }^{4} / \frac{\Delta}{s}$ 